\title{
Never Current Former Classification
}

National Cancer Institute

\section{Source}

National Cancer Institute. Never Current Former Classification. NCI Thesaurus. Code C83169.

The systematic arrangement of entities into groups such that each entity can be assigned the value Never, Current or Former. 